\title{
CIRURGIA ORTOGNÁTICA PARA CORREÇÃO DE DEFORMIDADE EM MAXILA EDÊNTULA
}

Luiza NASCIMENTO, Fabiano GALINA, Leandro KLUPPEL, Rafaela SCARIOT, Nelson REBELLATO

A cirurgia ortognática é um procedimento que tem como objetivo corrigir as deformidades dento-faciais, resultante de falha no posicionamento das arcadas dentárias e ossos da face em relação à base do crânio, interferindo na funcionalidade e na aparência estética do paciente. Paciente do gênero masculino, 38 anos, compareceu ao serviço de cirurgia e traumatologia bucomaxilofaciais da universidade federal do Paraná, apresentando ausência total de dentes superiores e parcial de inferiores. Procurou tratamento devido à dificuldade mastigatória e estética. Após análise de radiografias, modelos de estudo e análise facial, podemos constatar uma deficiência anteroposterior de maxila com uma boa relação esquelética da mandíbula em relação à face, além de uma prótese total superior e prótese parcial removível inferior mal adaptadas. O plano de tratamento foi composto da confecção de uma nova prótese total, descompensada, em maxila e uma prótese parcial removível para mandíbula. Após confecção das próteses, foi realizado procedimento, em ambiente hospitalar, sob anestesia geral, de avanço de $10 \mathrm{~mm}$ em maxila atingindo classe I com mandíbula. Uma melhor harmonia estética e funcional foram estabelecidas e novas próteses confeccionadas após cirurgia.

Palavras - chave: cirurgia ortognática; maxila edêntula, prótese total. 